\title{
The optometrist and primary eye care
}

Ophthalmologists are strongly opposed to any move by optometrists to treat anterior segment disease. Or are they? This year the optometric journal Optician has been examining this question by gauging opinions from grassroots professionals and from their representative bodies. At a time when UK universities are offering optometrists the first postgraduate courses in ocular therapeutics the results make interesting reading.

According to a survey conducted by Optician in August 1996, half of UK ophthalmologists believe that optometrists could use ocular therapeutics given suitable training. Yet many clearly remain implacably opposed to the concept $-49 \%$ of those surveyed saying they were against any suggested timescale for introducing such a move.

Not surprisingly, optometrists' opinions are less divided. A similar Optician survey earlier in 1996 showed that $91 \%$ of UK optometrists surveyed would be interested in using ocular therapeutics, again given suitable training. There was widespread support for managing a range of conditions such as conjunctivitis, blepharitis, and dry eye.

Despite their enthusiasm, many optometrists expressed concern over the issues of education, funding, and litigation and many rejected the notion of managing a wider spectrum of anterior segment disease. Yet eight out of 10 optometrists believed that a realistic timescale for a move into therapeutics was within 2 years.

Adding a further piece to the jigsaw, a poll conducted by London's City University in 1990 but published in 1996 showed that $63 \%$ of general practitioners believed optometrists should treat external eye conditions such as conjunctivitis, with a similar proportion saying they should be allowed to prescribe broad spectrum topical antibiotics.

The College of Optometrists supports an enhanced clinical role for its members and is already committed to developing higher qualifications in ocular therapeutics. Its policy is in line with the 'educate then legislate' tactic used by US optometrists in gaining approval for therapeutic use. The College is also to apply to the Medicines Control Agency to extend the range of ophthalmic drugs optometrists can use.

But there is evidence that their case will meet with opposition from some of the medical representative bodies. Commenting on Optician's survey of optometrists' attitudes to therapeutic use, the Royal College of Ophthalmologists said that the treatment of eye disease should only be carried out by medically trained doctors and that further 'medical' training for optometrists would only be helpful if they wanted to become doctors.

The ophthalmic group committee of the British Medical Association added that they remained unconvinced by arguments that US optometrists had already won the right to prescribe drugs. Instead, the way forward was to boost general practitioner training, they said.

A Department of Health proposal, in its consultation document 'Primary care: the future', that optometry could become 'the principal provider of primary ophthalmic care' drew similar fire. But the Royal College of General Practitioners has come out tentatively in favour of the concept, saying that both general practitioners and optom- etrists should be given the opportunity to develop their respective roles, a view supported by the National Association of Health Authorities and Trusts.

There are many arguments put forward in favour of optometrists treating anterior eye disease. Supporters say that this is a group of professionals working within the community with the potential to provide cost effective and high quality primary care. Their training in detecting and referring eye disease is superior to that of general practitioners, it is argued, and most are experienced at assessing the anterior eye through contact lens examination procedures.

While a minority of optometrists work alongside ophthalmologists in the Hospital Eye Service, many more working in the high street are already cooperating successfully with local ophthalmologists in shared care schemes for the monitoring of diagnosed eye diseases, such as diabetic retinopathy and chronic glaucoma. The effect is to improve access to continuing care, relieve the increasing pressure on hospital outpatient departments, and offer cost savings in the acute sector.

Optometrists also see those in other professions, such as nurse practitioners and community pharmacists, having greater responsibilities in the treatment of disease. Most optometrists already claim to manage minor eye conditions such as hay fever conjunctivitis and regard their inability to prescribe drugs, even when these are available over the counter to the public, as an anachronism.

Aside from arguments as to their suitability for the job, optometrists are experiencing pressures within optical practice for a change of role. Not only has the supply of spectacles been deregulated but the imposition of charges for eye examinations led to decreased patient attendance and a greater dependence on spectacle sales in what is now a highly competitive marketplace.

Dispensing opticians are steadily encroaching on the optometrist's traditional role through contact lens fitting, low vision assessment, and even refraction. Furthermore, many of the examination techniques employed by optometrists are now automated and tasks such as visual field assessment are being delegated to optical assistants.

The threat of deregulation of contact lens supply and recent moves by pharmacists to provide spectacles to prescription have added further fuel to optometrists' perception that their future role may contract rather than expand.

However, most optometrists realise that there are hurdles to overcome if a role in treating anterior segment disease is to come about, foremost of which must be training. So far, undergraduate courses have not all provided a grounding in pharmacology but moves are afoot to revise the syllabus at some universities from 1997. UK universities are now offering postgraduate courses in therapeutics - often taught by ophthalmologists - and, in September 1996, 100 optometrists sat the first examinations in the subject at City University.

On the question of funding, changes envisaged in the government's recent white paper, 'Choice and opportunity', would encourage greater use of professional skills and allow new flexibility in contracts between high 
street optometrists and health authorities. But other issues such as the need for increased professional indemnity insurance and the lack of continuity of patient care in high street optical practice remain to be addressed.

Will these obstacles and the opposition from sections of the medical profession eventually be overcome? Experience from the USA, where only one state does not allow optometrists to use ocular therapeutics, shows that they might. Last year saw the start of the debate in the UK. What is needed now is open discussion between all those involved, both locally and nationally, about the optometrist's role in future primary eye care provision.

A EWBANK

Editor

Optician, Reed Business Publishing,

Sutton, Surrey SM2 5AS 